\title{
Different cultivation methods to acclimatise ammonia-tolerant methanogenic consortia
}

Tian, Hailin; Fotidis, Ioannis; Mancini, Enrico; Angelidaki, Irini

Published in:

Bioresource Technology

Link to article, DOI:

10.1016/j.biortech.2017.02.034

Publication date:

2017

Document Version

Peer reviewed version

Link back to DTU Orbit

Citation (APA):

Tian, H., Fotidis, I., Mancini, E., \& Angelidaki, I. (2017). Different cultivation methods to acclimatise ammoniatolerant methanogenic consortia. Bioresource Technology, 232, 1-9.

https://doi.org/10.1016/j.biortech.2017.02.034

\section{General rights}

Copyright and moral rights for the publications made accessible in the public portal are retained by the authors and/or other copyright owners and it is a condition of accessing publications that users recognise and abide by the legal requirements associated with these rights.

- Users may download and print one copy of any publication from the public portal for the purpose of private study or research.

- You may not further distribute the material or use it for any profit-making activity or commercial gain

- You may freely distribute the URL identifying the publication in the public portal

If you believe that this document breaches copyright please contact us providing details, and we will remove access to the work immediately and investigate your claim. 


\section{Accepted Manuscript}

Different cultivation methods to acclimatise ammonia-tolerant methanogenic consortia

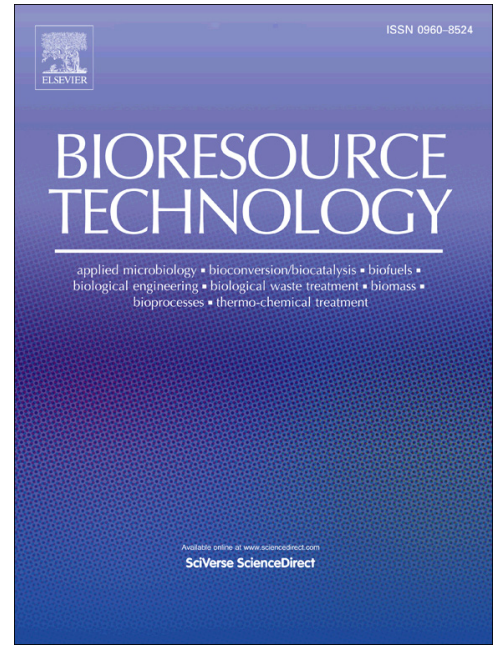

To appear in: $\quad$ Bioresource Technology

Received Date: $\quad 24$ December 2016

Revised Date: $\quad 7$ February 2017

Accepted Date: $\quad 8$ February 2017

Please cite this article as: Tian, H., Fotidis, I.A., Mancini, E., Angelidaki, I., Different cultivation methods to acclimatise ammonia-tolerant methanogenic consortia, Bioresource Technology (2017), doi: http://dx.doi.org/ 10.1016/j.biortech.2017.02.034

This is a PDF file of an unedited manuscript that has been accepted for publication. As a service to our customers we are providing this early version of the manuscript. The manuscript will undergo copyediting, typesetting, and review of the resulting proof before it is published in its final form. Please note that during the production process errors may be discovered which could affect the content, and all legal disclaimers that apply to the journal pertain. 


\title{
Different cultivation methods to acclimatise ammonia-tolerant methanogenic consortia
}

Hailin Tian, Ioannis A. Fotidis*, Enrico Mancini, Irini Angelidaki

Department of Environmental Engineering, Technical University of Denmark, Bygningstorvet Bygning 115, DK-2800 Kgs. Lyngby, Denmark

*Corresponding Author: Ioannis A. Fotidis, Department of Environmental Engineering, Technical University of Denmark, Bygningstorvet Bygning 115, DK-2800 Kgs. Lyngby, Denmark, Phone: (+45) 45251418; Fax: (+45) 45933850; e-mail: ioanf@env.dtu.dk

\begin{abstract}
Bioaugmentation with ammonia tolerant-methanogenic consortia was proposed as a solution to overcome ammonia inhibition during anaerobic digestion process recently. However, appropriate technology to generate ammonia tolerant methanogenic consortia is still lacking. In this study, three basic reactors (i.e. batch, fed-batch and continuous stirred-tank reactors (CSTR) operated at mesophilic $\left(37^{\circ} \mathrm{C}\right)$ and thermophilic $\left(55^{\circ} \mathrm{C}\right)$ conditions were assessed, based on methane production efficiency, incubation time, TAN/FAN (total ammonium nitrogen/free ammonia nitrogen) levels and maximum methanogenic activity. Overall, fedbatch cultivation was clearly the most efficient method compared to batch and CSTR.
\end{abstract}


Specifically, by saving incubation time up to $150 \%$, fed-batch reactors were acclimatised to nearly 2-fold higher FAN levels with a 37\%-153\% methanogenic activity improvement, compared to batch method. Meanwhile, CSTR reactors were inhibited at lower ammonia levels. Finally, specific methanogenic activity test showed that hydrogenotrophic methanogens were more active than aceticlastic methanogens in all FAN levels above $540 \mathrm{mg}$ $\mathrm{NH}_{3}-\mathrm{N} \mathrm{L}^{-1}$.

\section{Keywords}

Batch reactor; Fed-batch reactor; CSTR; Specific methanogenic activity; Incubation time

\section{Introduction}

Anaerobic digestion (AD) is one of the most commonly used methods to treat a vast array of organic waste-slurries and wastewaters derived from different sources (e.g. agricultural waste, industrial waste, food waste, municipal sewage sludge etc.), which result in energy recovery (biogas; a mixture of $\mathrm{CH}_{4}$ and $\mathrm{CO}_{2}$ ) and in a nutrient-rich digestate used as biofertilizer (Bekkering et al., 2015). Additionally, AD reduces the greenhouse gas emissions and has lower energy requirements compared to other waste treatment methods (Westerholm et al., 2012). However, when ammonia-rich waste (e.g. animal manure, slaughterhouse wastewater etc.) are used as AD substrates, an instability or even complete process failure could occur from high total ammonia (TAN $=\mathrm{NH}_{3}+\mathrm{NH}_{4}{ }^{+}$) concentrations (Yenigün and Demirel, 2013). It has been reported that many commercial biogas plants lose up to $30 \%$ of their methane potential operating under an ammonia induced "inhibited steady state" (Fotidis et al., 2013a). 
Among the microorganisms mediating the $\mathrm{AD}$, methanogens are the most sensitive to ammonia and thus, methanogenesis becomes the rate-limiting step of the overall process (Singh and Olsen, 2011). There are two major methanogenic pathways using acetate as methanogenic substrate: aceticlastic methanogenesis (AM) and syntrophic acetate oxidation coupled by hydrogenotrophic methanogenesis (SAO-HM). AM pathway has been reported to be much more sensitive to ammonia compared to the SAO-HM pathway (Borja et al., 1996). Furthermore, many studies showed that free ammonia (FAN), which increases alongside with pH and temperature, is the most toxic form of TAN (Massé et al., 2014).

To solve the ammonia toxicity problem, many solutions have been proposed (e.g. reactor content dilution, addition of absorbents, air striping etc.) (Angelidaki and Ahring, 1992; Nielsen and Angelidaki, 2008; Zhang et al., 2012). However, these methods can alleviate ammonia inhibition to a certain extent, but they are either cost-expensive or some of them far from practical applicability. In the recent years, bioaugmentation of ammonia tolerant methanogenic consortia has been proposed as a promising method to attack this challenge. Bioaugmentation is the process of adding microorganisms with specific function or property into a biological system to improve the performance of the system (Stephenson and Stephenson, 1992). It has been successfully used in many areas, such as hazardous waste control, aerobic wastewater disposal (Ivanov et al., 2006; Schauer-Gimenez et al., 2010) and also in AD process to recover from organic overload and increase methane yield (Tale et al., 2015; Zhang et al., 2015).

Latterly, there have been different attempts to use bioaugmentation to solve the ammonia toxicity problem in $\mathrm{AD}$ reactors, with some encouraging results (Westerholm et al., 2012; Fotidis et al., 2014). These studies have identified that one of the major bottlenecks for a successful bioaugmentation process is the availability of ammonia-tolerant methanogenic consortia. Furthermore, it was suggested that bioaugmentation with mixed microbial consortia 
is more attractive due to its robustness compared to pure cultures (Yang et al., 2016).

However, to date, no study can be found assessing/proposing the most efficient method (in terms e.g. of incubation time, TAN and FAN levels achieved, methanogenic activity, etc.) to acclimatise ammonia tolerant methanogenic consortia.

Generally, there are three basic types of reactor configurations/processes that could practically be used to acclimatise ammonia tolerant methanogens, i.e. batch, fed-batch and continuous reactors. Batch cultivation is used to grow microorganisms where an initial supply of carbon source and nutrients is provided in the beginning and when these are consumed the culture cease growing (Minihane and Brown, 1986). Interestingly, in the existing bioaugmentation studies, batch reactors were used to acclimatise ammonia tolerant cultures, without assessing the efficiency of the process. However, considering the "one-time feeding", high cell density is not easy to get with batch process because, in specific cases, toxicity caused by the metabolic by-products can occur (Ding and Tan, 2006). Fed-batch is a cultivation process which starts with a batch culture, and then fed continuously or sequentially with substrate without fermentation broth removal until the reactor is filled up (Lee et al., 1999; Ding and Tan, 2006). Fed-batch reactors are widely used for biomass and specific metabolic product cultivation (Gordillo et al., 1998). However, different technical challenges could arise during fed-batch process, because some parameters, like the estimation or calculation of growth rate, sterility challenge due to pumping and other facilities and more attendance requirement needed compared to batch cultivations (Yoon et al., 1994;

Wechselberger et al., 2013). Finally, a typical continuous AD reactor (e.g. continuous stirred tank reactor - CSTR), offers a more stable environment without too much toxicant accumulation due to daily input and output. However, washout effect of useful microorganism is the main drawback of this configuration (Fynn and Whitmore, 1984). 
Therefore, the main aim of the present study was to assess the efficiency of the three different cultivation methods (i.e. batch, fed-batch and CSTR) to acclimatise methanogenic consortia to high ammonia levels. Both mesophilic $\left(37^{\circ} \mathrm{C}\right)$ and thermophilic $\left(53^{\circ} \mathrm{C}\right)$ inocula were used to evaluate the effect of temperature in the different acclimation processes. The $\mathrm{CH}_{4}$ production efficiency, incubation time, TAN/FAN levels achieved and methanogenic activity, were used as criteria to evaluate the three acclimation processes. On the other hand, different effects between stepwise and direct-exposure of methanogens to ammonia during batch cultivation was reported by a previous study (Fotidis et al., 2013b), thus both acclimation approaches were tested during the batch experimental assay. Finally, the specific methanogenic activity test was applied to the final consortia, derived from the acclimation methods, to evaluate the activity of methanogenic populations from each acclimatisation process.

\section{Materials and methods}

\subsection{Inoculum and substrate}

The inocula used in this study were obtained from two different Danish full-scale biogas plants; the mesophilic one $\left(37 \pm 1^{\circ} \mathrm{C}\right)$ from Hashøj biogas plant, while the thermophilic one $\left(53 \pm 1^{\circ} \mathrm{C}\right)$ from Snertinge biogas plant. Both plants are fed with $70-90 \%$ animal manure and $10-30 \%$ food industrial organic waste. The basic characteristics of these two inocula are presented in Table 1. The medium used in all the experiments was basal anaerobic medium (BA medium), which is a solution of basic nutrients for microbial growth (Angelidaki et al., 1990). Sodium acetate and ammonium chloride were used as carbon and ammonia sources, respectively. 


\subsection{Experimental setup}

Three different experimental assays (batch, fed-batch and CSTR) were performed in this study to compare their efficiency on acclimating the two-different initial inocula to high ammonia levels. In all three assays, the inocula were incubated at their original TAN levels for lab-scale environment adaptation and determination of the baseline/uninhibited methane production. In all experimental assays, a low organic load (batch) or organic loading rateOLR (fed-batch, CSTR) was chosen to avoid the ammonia-VFA synergistic inhibition effect (Lu et al., 2013) and thus, only assess the influence of ammonia. Overall, five different ammonia acclimation levels were tested for the mesophilic and four for the thermophilic inoculum, respectively (Table 2).

\subsubsection{Batch experimental assay}

Two subseries of experiments were performed during batch experimental assay. The first one was a direct-exposure of the baseline inoculum to different ammonia levels. The second was stepwise exposure of the baseline inoculum to increasing ammonia concentrations through successive batch cultivations, i.e. the inoculum used for the next ammonia level derived from the previous ammonia level batch cultivation. In this assay, glass serum bottles were used with $118 \mathrm{~mL}$ and $40 \mathrm{~mL}$ total and working volume, respectively. Inoculum $(8 \mathrm{~mL})$ and BA medium $(32 \mathrm{~mL})$ were added in each reactor, and then flushed with a mixture gas of $\mathrm{N}_{2} / \mathrm{CO}_{2}(80 / 20 \% \mathrm{v} / \mathrm{v})$ to create anoxic conditions. Yeast extract $\left(0.2 \mathrm{~g} \mathrm{~L}^{-1}\right)$ and vitamin solution $\left(0.1 \mathrm{~g} \mathrm{~L}^{-1}\right)$ (Wolin et al., 1963) were introduced in the bottles and finally, $\mathrm{Na}_{2} \mathrm{~S} \bullet 9 \mathrm{H}_{2} \mathrm{O}$ $\left(62.5 \mathrm{mg} \mathrm{L}^{-1}\right)$ was added as a reducing agent. All the reactors were closed with butyl rubber stoppers, sealed with aluminium caps, and incubated in their corresponding temperature. All experiments were performed in triplicates. 


\subsubsection{Fed-batch experimental assay}

The fed-batch experiments were performed in two glass bottle reactors, one for the mesophilic and one for the thermophilic inoculum, with $2.3 \mathrm{~L}$ total volume. Starting with 45 $\mathrm{mL}$ inoculum, the later feeding was adopted by an exponential feeding strategy (i.e. the reactor content was converted at a specific rate to active inoculum). The feeding (as shown in

Fig. S1, supplementary material) was performed every two days manually, with an increasing volume of feedstock. A constant OLR of $0.5 \mathrm{~g} \mathrm{HAc} \mathrm{L}^{-1} \mathrm{~d}^{-1}$ was used throughout the experimental period for both reactors. The ammonia levels (Table 2) were increased every 20 and 15 days, for mesophilic and thermophilic reactor, respectively. Before each new ammonia level, a small amount $(15 \mathrm{~mL})$ of sample was taken from the fed-batch reactor for analyses.

\subsubsection{CSTR experimental assay}

Two lab-scale CSTR reactors were used, one for the mesophilic and another for the thermophilic inoculum with 20 and 15 days HRT, respectively. Each reactor had a 2.3 and 1.8 L total and working volume, respectively, and an OLR of $0.5 \mathrm{~g} \mathrm{HAc} \mathrm{L}^{-1} \mathrm{~d}^{-1}$ was used throughout the experiment. Each reactor was consisted of an influent, an effluent bottle, a feeding peristaltic pump, an electrical heating jacket, a water-displacement gas meter and two magnetic stirrers for the homogenization of substrate and mixing of the reactor. To proceed to the next acclimation step (Table 2), the ammonia was spiked simultaneously into the reactors and the substrate.

\subsection{Specific methanogenic activity test}

A SMA test on specific substrates (formate, acetate and $\mathrm{H}_{2} / \mathrm{CO}_{2}$ ) was carried out for the final methanogenic consortia derived from the acclimation assays, to investigate the combined effect of high ammonia levels and each acclimation process on the methanogenic populations. Samples for SMA test were taken from the reactors at the end of each acclimation assay. The 
test for fed-batch and CSTR was done in batch serum vials of $118 \mathrm{~mL}$ total volume and 40 $\mathrm{mL}$ working volume. The cultures derived for the batch experimental assay were incubated in vials with $58 \mathrm{~mL}$ and $20 \mathrm{~mL}$ total and working volume, respectively. Active biomass constituted the $25 \%$ of the working volume, and $75 \%$ was BA medium in all SMA tests. All the vials (liquid phase and headspace) were flushed with a mixture gas of $\mathrm{N}_{2} / \mathrm{CO}_{2}(80 / 20 \%$, v/v) to create anaerobic conditions. Formate $(80 \mathrm{mM})$, acetate $(20 \mathrm{mM})$ and $\mathrm{H}_{2} / \mathrm{CO}_{2}(80 / 20 \%$, v/v, under 1 atm) were used individually, as carbon sources (Luo et al., 2011). Finally, vials with only inoculum and BA medium were used as blanks and all the tests were made in triplicates.

\subsection{Analyses}

TS, VS, TAN and TKN were measured through the American Public Health AssociationAPHA's Standard Method (APHA, 2005). The $\mathrm{pH}$ fluctuation in the reactors was determined through PHM99 LAB pH meter. Total VFA concentration inside the reactors was determined by a gas-chromatograph (HP 5890 series II) equipped with flame ionization detector and a FFAP fused silica capillary column, $(30 \mathrm{~m} \times 0.53 \mathrm{~mm}$ i.d., film thickness $1.5 \mu \mathrm{m})$, and nitrogen was used as carrier gas. The biogas composition was measured by a gaschromatograph (Trace 1310 GC-TCD, Thermo Fisher, Denmark) equipped with TracePLOT TG-BOND Q $26004-6030$ column (30 m × $0.32 \mathrm{~mm}$ I.D., film thickness $10.0 \mu \mathrm{m})($ Thermo Fisher). Helium was used as carrier gas.

\subsection{Calculations and statistical analyses}

\subsubsection{Free ammonia calculation}

The FAN concentration was calculated by the following equation: 
$\mathrm{FAN}=\frac{\mathrm{TAN}}{1+\frac{10^{-\mathrm{pH}}}{\mathrm{K}_{\mathrm{a}}}}$

Eq. (1)

Where $\mathrm{Ka}$ is the dissociation constant affected by temperature, and equals to $1.29 \times 10^{-9}$ and $3.91 \times 10^{-9}$ for mesophilic and thermophilic condition in the present study, respectively.

\subsubsection{Maximum theoretical methane production}

The maximum theoretical methane production used in the batch and fed-batch reactors' experiments was calculated based on the stoichiometry of biological $\mathrm{CH}_{4}$ production from acetate (Angelidaki et al., 2011), where $1 \mathrm{~g}$ acetate can produce maximum $373.33 \mathrm{NmL} \mathrm{CH}_{4}$. Furthermore, the real methane production of the batch reactors experiment, was expressed as percentage of the maximum theoretical methane production.

\subsubsection{SMA test calculation}

Considering the biofibers was part of the inoculum (e.g. lignin cellulose in the original inoculum), VS content cannot stand for the microbe cell quantity in this study. Therefore, the methanogenic activity was defined as the linear methane accumulation rate versus time, divided by the volume of the biomass tested.

\subsubsection{Statistical analysis}

All statistical analyses and the plotted data were made using the OriginLab program (OriginLab Corporation, Northampton, Massachusetts). Student's t-test was used for estimation of statistically significant difference $(p<0.05)$ when compare SMA test result between the different acclimation methods. One-way ANOVA was used to evaluate the statistically significant differences $(p<0.05)$ in methane production and VFA accumulation results derived from the fed-batch and CSTR reactors. 


\section{Results and discussion}

\subsection{Batch reactors performance}

In general, the methane production in all batch reactors reached the theoretical value through different incubation times (Fig. 1). During direct-exposure acclimation method, the incubation time was prolonged alongside the ammonia levels, due to the longer lag phases (Fig. 1A and Fig. 1B). This was in accordance with a previous study, which reported a longer lag phase at high ammonia levels $\left(6-7 \mathrm{NH}_{4}{ }^{+}-\mathrm{N} \mathrm{L}^{-1}\right)$ than low levels $\left(1-3 \mathrm{NH}_{4}{ }^{+}-\mathrm{N} \mathrm{L}^{-1}\right)(\mathrm{Lu}$ et al., 2013). An interesting finding was that a shorter incubation time was found at MP4 $\left(\mathrm{TAN}=6.56 \mathrm{~g} \mathrm{NH}_{4}{ }^{+}-\mathrm{N} \mathrm{L}^{-1}\right)$ compared to MP2 $\left(\mathrm{TAN}=4.56 \mathrm{~g} \mathrm{NH}_{4}{ }^{+}-\mathrm{NL}^{-1}\right)$ and MP3 $\left(\mathrm{TAN}=5.56 \mathrm{~g} \mathrm{NH}_{4}{ }^{+}-\mathrm{N} \mathrm{L}^{-1}\right.$ ) (Fig. 1A). Considering that FAN is the most toxic form of TAN (Kroeker et al., 1979); this result could be explained by the relatively low FAN concentration (100 mg NH $\left.\mathrm{L}^{-1}\right)$ in MP4, compared to MP2 (180 $\left.\mathrm{mg} \mathrm{NH}_{3} \mathrm{~L}^{-1}\right)$ and MP3 (200 $\left.\mathrm{mg} \mathrm{NH}_{3} \mathrm{~L}^{-1}\right)$.

The stepwise acclimation method shortened the incubation time within each individual ammonia level both under mesophilic and thermophilic condition compared to directexposure (Fig. 1). For example, at the higher ammonia levels, 20 days were needed to fulfil the acclimation process during MP5 in stepwise-exposure, instead of 78 days in the same ammonia level in direct-exposure, which saved almost $300 \%$ of the incubation time.

However, even though the shorter incubation time within each individual acclimation step, the stepwise-exposure still took more time to acclimatise the consortia to high ammonia levels than the direct method. The incubation time for the highest ammonia levels was 78 and 91 days (Fig. 1A and Fig. 1B) under direct-exposure for mesophilic and thermophilic condition, respectively, while it was 125 and 158 days under stepwise-exposure (Fig. 1C and Fig. 1D). This was probably due to the accumulation of lag phases during every single step of the stepwise-exposure. On the other hand, it was reported that direct-exposure, results in higher 
diversity of methanogens compared to stepwise acclimation (Fotidis et al., 2013b), which may provide a better chance for the methanogens to adapt to the high ammonia environment. Therefore, based on the results from the current study, the direct-exposure acclimation method seems to be preferable than the stepwise-exposure, with respect to methane production and especially the incubation time. However, it is still possible to have a process failure when using the direct-exposure acclimation method (Liu and Sung, 2002), since it depends on the initial microbiological composition of the inoculum (i.e. if ammonia tolerant methanogens are present even in low abundance).

\subsection{Fed-batch reactors performance}

Throughout the whole experiment, methane accumulation for both fed-batch reactors followed the theoretical methane production with only small fluctuations and finally reached a high TAN concentration of 6.56 and $6.32 \mathrm{~g} \mathrm{NH}_{4}^{+}-\mathrm{N} \mathrm{L}^{-1}$ for mesophilic and thermophilic conditions, respectively (Fig. 2A and Fig. 2B). The relatively higher methane accumulation (above the maximum theoretical) during baseline period (MP1, TP1) can be attributed to the background production from the initial inoculum. Even though a gas production delay was

found at TP2 $\left(4.32 \mathrm{~g} \mathrm{NH}_{4}{ }^{+}-\mathrm{N} \mathrm{L}^{-1}\right)$, the reactor recovered immediately during TP3. At the end of the experiment, the methane production was more than $83 \%$ of the theoretical expected production for both fed-batch reactors, which implied a stable AD environment without any serious ammonia inhibition. Notably, in the thermophilic reactor, the final FAN concentration was more than $1600 \mathrm{mg} \mathrm{NH}_{3}-\mathrm{N} \mathrm{L}^{-1}$. To our knowledge, it has never been reported before an efficient biomethanation process acclimatised to these extremely high FAN levels at such a short time frame (64 days). This result suggests that the fed-batch cultivation could be appropriate as acclimatisation method.

Furthermore, $\mathrm{pH}$ ranged from 8.2 to 7.8 and VFA fluctuated from 0 to $2200 \mathrm{mg} \mathrm{HAc} \mathrm{L}^{-1}$ for both reactors throughout the experiment (Fig. 2C and Fig. 2D), which were within the 
appropriate levels reported by previous studies (Nissilä et al., 2012), indicating a stable digestion process. However, it should be mentioned that between the different ammonia levels there was significant difference $(p<0.05)$ in the VFA concentrations, which means that ammonia increase applied some inhibitory pressure on methanogenesis, but the process adapted successfully.

To sum up, the initial inocula were successfully acclimatised to 6.56 and $6.32 \mathrm{~g} \mathrm{NH}_{4}^{+}-\mathrm{N} \mathrm{L}^{-}$ ${ }^{1}$ ammonia concentrations under mesophilic and thermophilic condition, respectively. During the whole process (except TP2), no profound process instability due to high ammonia was observed. The uninhibited process could be explained by the relatively stable microorganism growth, which was controlled by exponential feeding strategy during fed-batch acclimation method (Ding and Tan, 2006). Another reason contributing to the process stability could be the lack of effluent (no washout effect), which ensured that all microorganisms remained in the reactor. The results derived from the fed-batch acclimation method further proved that adjusting the feeding to an exponential strategy played an important role for a better acclimation process (Liu, 2013).

\subsection{CSTR reactors performance}

Both CSTR reactors did not pass the second acclimation step $\left(4.56 \mathrm{~g} \mathrm{NH}_{4}{ }^{+}-\mathrm{N} \mathrm{L}^{-1}\right.$ for mesophilic and $4.32 \mathrm{~g} \mathrm{NH}_{4}{ }^{+}-\mathrm{N} \mathrm{L}^{-1}$ for thermophilic) due to strong ammonia inhibition. An ammonia induced “inhibited steady state” (Hansen et al., 1998) was established during MP2 and TP2, with a methane yield of around $30 \%$ of the theoretical, until the end of the experiment (Fig. 3A and Fig. 3B). The low methane yield indicated that methanogens were experiencing strong inhibition from the ammonia. In parallel, VFA concentration increased in both reactors from near zero, during the baseline period (MP1, TP1), to levels above $1500 \mathrm{mg}$ HAc $\mathrm{L}^{-1}$ during the second acclimation step, which is an established threshold for non-healthy continuous AD process (Angelidaki et al., 2005). The pH (Fig. 3C and Fig. 3D), was within 
the normal limits (6.5-8.5) for the AD process for both reactors throughout the experiment (Lay et al., 1998). However, the thermophilic reactor had a maximum $\mathrm{pH}$ of 8.44, which had a direct effect on the FAN levels (higher than $2000 \mathrm{mg} \mathrm{NH}_{3}-\mathrm{N} \mathrm{L}^{-1}$ ) that consequently could have led to a serious inhibition.

The main reason for the failure of both CSTR reactors could be the washout of methanogenic communities (Fynn and Whitmore, 1984), which resulted in the loss of ammonia tolerant methanogens that were in low abundance in the initial inocula. Therefore, it can be concluded that CSTR reactors are not suitable for the acclimation of ammonia-tolerant methanogenic consortia in a realistic timeframe that will allow them to be used as bioaugmentation inocula. However, if time is not an issue, then it could be possible to use longer HRTs and slower exposure to higher ammonia levels to efficient acclimatise methanogenic inocula, as it has been shown before (Calli et al., 2005).

\subsection{SMA test}

Activity test (Fig. 4) indicated that hydrogenotrophic methanogens were significantly more active than aceticlastic methanogens among most of the acclimation methods at higher ammonia levels. That agreed with previous studies (Borja et al., 1996; Calli et al., 2003; Werner et al., 2014), which showed that aceticlastic methanogens were more sensitive to higher ammonia levels compared to hydrogenotrophic methanogens. Aceticlastic activity was higher only in mesophilic batch reactors, with no significant difference $(p>0.05)$ between direct and stepwise acclimation approach. It is generally accepted that under optimum digestion conditions aceticlastic methanogens have higher growth rates compared to syntrophic acetate oxidizing bacteria, which are in an exclusive syntrophic collaboration with the hydrogenotrophic methanogens (Schnürer and Nordberg, 2008; Kato et al., 2014). This consequently means that aceticlastic have higher growth rates compared to the hydrogenotrophic methanogens, under the same optimum conditions. Thus, the higher 
aceticlastic activity could be explained by the low FAN levels $\left(210 \mathrm{mg} \mathrm{NH}_{3}-\mathrm{N} \mathrm{L}^{-1}\right)$ during the mesophilic batch acclimation that did not affect the growth rates of the aceticlastic methanogens. Overall, based on the SMA result and FAN levels in the present study, hydrogenotrophic methanogens had higher activity under high FAN levels (above $540 \mathrm{mg}$ $\mathrm{NH}_{3}-\mathrm{N} \mathrm{L}^{-1}$ ), while aceticlastic methanogens were more active at low FAN levels (below 210 $\left.\operatorname{mg~} \mathrm{NH}_{3}-\mathrm{N} \mathrm{L}^{-1}\right)$.

Finally, in the samples with higher hydrogenotrophic activity, formate was consumed much faster than $\mathrm{H}_{2} / \mathrm{CO}_{2}$. Since it is known that most of the hydrogenotrophic methanogens can also utilize formate (Pan et al., 2016), the higher formate consumption rate could be attributed to the additional time needed for $\mathrm{H}_{2}$ transfer from gas to liquid phase, compared to formate which was already available in the liquid phase (Boone et al., 1989; Pauss et al., 1990).

\subsection{Batch vs fed-batch vs CSTR}

An overall evaluation (Table 3) of the three different reactor configurations, based on the assessment indexes that were set before (i.e. methane production efficiency, incubation time, TAN/FAN levels achieved and methanogenic activity), clearly showed that fed-batch was the best acclimation method compared to batch and CSTR methods, under both mesophilic and thermophilic conditions. With respect to the production efficiency, only $30 \%$ of the theoretical production was detected during CSTR acclimation method, while more than $83 \%$ in batch and fed-batch reactors was achieved. Furthermore, CSTR reactors didn't operate stably (during the chosen acclimation approach) even with only $1 \mathrm{~g} \mathrm{NH}_{4}^{+}-\mathrm{N} \mathrm{L}^{-1}$ increase.

Even though high activity results can be found among CSTR reactors, it was explained by the combined outcome of high microbial density due to high initial inoculation ratio in the CSTR, ideal growth conditions during the SMA test (Angelidaki and Ahring, 1993; Boe et al., 2009) and the fact that ammonia inhibition is reversible when the ammonia levels decrease (Parkin 
et al., 1983; Wu et al., 2009), instead of the result of acclimation. Thus, CSTR method is not suitable to efficiently acclimatise ammonia tolerant methanogenic consortia in a realistic timeframe, compared to the alternative methods.

Among the successful acclimation methods, the shortest incubation period was achieved together with the highest FAN levels and the highest methanogenic activity, with fed-batch reactors for both mesophilic and thermophilic conditions. Even though mesophilic batch direct-exposure method had a few days shorter incubation time than fed-batch, the FAN levels and the maximum methanogenic activity of the mesophilic fed-batch was $164 \%$ and $138 \%$ higher than batch direct-exposure method, respectively. The thermophilic Fed-batch acclimation method not only had the highest FAN levels and activity, but also had more than $40 \%$ shorter incubation time compared to batch acclimation methods. Thus, based on the comprehensive comparison of production efficiency, incubation time, TAN/FAN level and methanogenic activity between the different acclimation methods, it can be concluded that fed-batch could be the acclimation method that will potentially supply the necessary ammonia-tolerant bioaugmentation inocula in the near future.

\section{Conclusions}

The present study assessed different methods to acclimatise ammonia-tolerant methanogenic consortia and found that fed-batch is the best acclimation method based on the production efficiency, incubation time, TAN/FAN levels achieved and methanogenic activity. Fed-batch reactor worked efficiently at FAN levels as high as $1633 \mathrm{mg} \mathrm{NH}_{3} \mathrm{~L}^{-1}$ with a higher methanogenic activity compared to others. SMA test indicated that hydrogenotrophic activity was significantly higher than aceticlastic activity, during fed-batch acclimation process. Thus, this study offers an efficient method to create ammonia-tolerant methanogenic consortia, 
which is necessary for a successful bioaugmentation process to alleviate ammonia toxicity problem in biogas reactors.

\section{Acknowledgements}

The authors thank Hector Garcia for his technical support during the experiments. This work was supported by Energinet.dk under the project framework ForskEL "MicrobStopNH $\mathrm{N}_{3}$ Innovative bioaugmentation strategies to tackle ammonia inhibition in anaerobic digestion process" (program no. 2015-12327). Hailin Tian would like to thank for the financial support from China Scholarship Council.

\section{References}

[1] Angelidaki, I., Ahring, B.K., 1992. Effect of the clay mineral bentonite on ammonia inhibition of anaerobic thermophilic reactors degrading animal waste. Biodegradation $3,409-414$.

[2] Angelidaki, I., Ahring, B.K., 1993. Thermophilic anaerobic digestion of livestock waste: the effect of ammonia. Appl. Microbiol. Biotechnol. 38, 560-564.

[3] Angelidaki, I., Boe, K., Ellegaard, L., 2005. Effect of operating conditions and reactor configuration on efficiency of full-scale biogas plants. Water Sci. Technol. 52, 189.

[4] Angelidaki, I., Karakashev, D., Batstone, D.J., Plugge, C.M., Stams, A.J., 2011. Biomethanation and its potential. Methods Enzymol. 494, 327-351.

[5] Angelidaki, I., Petersen, S.P., Ahring, B.K., 1990. Effects of lipids on thermophilic anaerobic digestion and reduction of lipid inhibition upon addition of bentonite. Appl. Microbiol. Biotechnol. 33, 469-472.

[6] APHA, 2005. Standard Methods for the Examination of Water and Wastewater. American Public Health Association, Washington, DC. 
[7] Bekkering, J., Hengeveld, E.J., van Gemert, W.J.T., Broekhuis, A.A., 2015. Will implementation of green gas into the gas supply be feasible in the future? Appl. Energy 140, 409-417.

[8] Boe, K., Karakashev, D., Trably, E., Angelidaki, I., 2009. Effect of post-digestion temperature on serial CSTR biogas reactor performance. Water Res. 43, 669-76.

[9] Boone, D.R., Johnson, R.L., Liu, Y., 1989. Diffusion of the interspecies electron carriers $\mathrm{H} 2$ and formate in methanogenic ecosystems and its implications in the measurement of Km for H2 or formate uptake. Appl. Environ. Microbiol. 55, 17351741.

[10] Borja, R., Sánchez, E., Weiland, P., 1996. Influence of ammonia concentration on thermophilic anaerobic digestion of cattle manure in upflow anaerobic sludge blanket (UASB) reactors. Process Biochem. 31, 477-483.

[11] Calli, B., Mertoglu, B., Inanc, B., Yenigun, O., 2005. Effects of high free ammonia concentrations on the performances of anaerobic bioreactors. Process Biochem. 40, $1285-1292$.

[12] Calli, B., Mertoglu, B., Tas, N., Inanc, B., Yenigun, O., Ozturk, I., 2003. Investigation of variations in microbial diversity in anaerobic reactors treating landfill leachate. Water Sci. Technol. 48, 105.

[13] Ding, S., Tan, T., 2006. 1-lactic acid production by Lactobacillus casei fermentation using different fed-batch feeding strategies. Process Biochem. 41, 1451-1454.

[14] Fotidis, I.A., Karakashev, D., Angelidaki, I., 2013a. The dominant acetate degradation pathway/methanogenic composition in full-scale anaerobic digesters operating under different ammonia levels. INT J ENVIRON SCI TE 11, 2087-2094. 
[15] Fotidis, I.A., Karakashev, D., Kotsopoulos, T.A., Martzopoulos, G.G., Angelidaki, I., 2013b. Effect of ammonium and acetate on methanogenic pathway and methanogenic community composition. FEMS Microbiol. Ecol. 83, 38-48.

[16] Fotidis, I.A., Wang, H., Fiedel, N.R., Luo, G., Karakashev, D.B., Angelidaki, I., 2014. Bioaugmentation as a solution to increase methane production from an ammonia-rich substrate. Environ. Sci. Technol. 48, 7669-76.

[17] Fynn, G.H., Whitmore, T.N., 1984. Retention of methanogens in colonised reticulated polyurethane foam biomass support particle. Biotechnol. Lett. 6, 81-86.

[18] Gordillo, M.A., Sanz, A., Sanchez, A., Valero, F., Montesinos, J.L., Lafuente, J., Solà, C., 1998. Enhancement of Candida rugosa lipase production by using different control fed-batch operational strategies. Biotechnol. Bioeng. 60, 156-168.

[19] Hansen, K.H., Angelidaki, I., Ahring, B.K., 1998. Anaerobic digestion of swine manure: inhibition by ammonia. Water Res. 32, 5-12.

[20] Ivanov, V., Wang, X.H., Tay, S.T., Tay, J.H., 2006. Bioaugmentation and enhanced formation of microbial granules used in aerobic wastewater treatment. Appl. Microbiol. Biotechnol. 70, 374-81.

[21] Kato, S., Sasaki, K., Watanabe, K., Yumoto, I., Kamagata, Y., 2014. Physiological and transcriptomic analyses of the thermophilic, aceticlastic methanogen Methanosaeta thermophila responding to ammonia stress. Microbes Environ. 29, 162167.

[22] Kroeker, E.J., Schulte, D.D., Sparling, A.B., Lapp, H.M., 1979. Anaerobic Treatment Process Stability. J Water Pollut Control Fed 51, 718-727.

[23] Lay, J.J., Li, Y.Y., Noike, T., 1998. The influence of $\mathrm{pH}$ and ammonia concentration on the methane production in high-solids digestion processes. Water Environ. Res. 70, $1075-1082$. 
[24] Lee, J., Lee, S.Y., Park, S., Middelberg, A.P.J., 1999. Control of fed-batch fermentations. Biotechnol. Adv. 17, 29-48.

[25] Liu, S., 2013. Bioprocess engineering: kinetics, biosystems, sustainability, and reactor design. Newnes.

[26] Liu, T., Sung, S., 2002. Ammonia inhibition on thermophilic aceticlastic methanogens. Water Sci. Technol. 45, 113-120.

[27] Lu, F., Hao, L., Guan, D., Qi, Y., Shao, L., He, P., 2013. Synergetic stress of acids and ammonium on the shift in the methanogenic pathways during thermophilic anaerobic digestion of organics. Water Res. 47, 2297-306.

[28] Luo, G., Xie, L., Zhou, Q., Angelidaki, I., 2011. Enhancement of bioenergy production from organic wastes by two-stage anaerobic hydrogen and methane production process. Bioresour. Technol. 102, 8700-6.

[29] Massé, D.I., Rajagopal, R., Singh, G., 2014. Technical and operational feasibility of psychrophilic anaerobic digestion biotechnology for processing ammonia-rich waste. Appl. Energy 120, 49-55.

[30] Minihane, B.J., Brown, D.E., 1986. Fed-batch culture technology. Biotechnol. Adv. 4, 207-218.

[31] Nielsen, H.B., Angelidaki, I., 2008. Strategies for optimizing recovery of the biogas process following ammonia inhibition. Bioresour. Technol. 99, 7995-8001.

[32] Nissilä, M.E., Li, Y.-C., Wu, S.-Y., Lin, C.-Y., Puhakka, J.A., 2012. Hydrogenic and methanogenic fermentation of birch and conifer pulps. Appl. Energy 100, 58-65.

[33] Pan, X., Angelidaki, I., Alvarado-Morales, M., Liu, H., Liu, Y., Huang, X., Zhu, G., 2016. Methane production from formate, acetate and H2/CO2; focusing on kinetics and microbial characterization. Bioresour. Technol. 218, 796-806. 
[34] Parkin, G.F., Speece, R.E., Yang, C.H.J., Kocher, W.M., 1983. Response of methane fermentation systems to industrial toxicants. J Water Pollut Control Fed 55, 44-53.

[35] Pauss, A., Andre, G., Perrier, M., Guiot, S.R., 1990. Liquid-to-gas mass transfer in anaerobic processes: inevitable transfer limitations of methane and hydrogen in the biomethanation process. Appl. Environ. Microbiol. 56, 1636-1644.

[36] Schauer-Gimenez, A.E., Zitomer, D.H., Maki, J.S., Struble, C.A., 2010.

Bioaugmentation for improved recovery of anaerobic digesters after toxicant exposure. Water Res. 44, 3555-3564.

[37] Schnürer, A., Nordberg, Å., 2008. Ammonia, a selective agent for methane production by syntrophic acetate oxidation at mesophilic temperature. Water Sci. Technol. 57, $735-740$.

[38] Singh, A., Olsen, S.I., 2011. A critical review of biochemical conversion, sustainability and life cycle assessment of algal biofuels. Appl. Energy 88, 3548-3555.

[39] Stephenson, D., Stephenson, T., 1992. Bioaugmentation for enhancing biological wastewater treatment. Biotechnol. Adv. 10, 549-559.

[40] Tale, V.P., Maki, J.S., Zitomer, D.H., 2015. Bioaugmentation of overloaded anaerobic digesters restores function and archaeal community. Water Res. 70, 138-147.

[41] Wechselberger, P., Sagmeister, P., Herwig, C., 2013. Real-time estimation of biomass and specific growth rate in physiologically variable recombinant fed-batch processes. Bioprocess Biosyst Eng 36, 1205-1218.

[42] Werner, J.J., Garcia, M.L., Perkins, S.D., Yarasheski, K.E., Smith, S.R., Muegge, B.D., Stadermann, F.J., DeRito, C.M., Floss, C., Madsen, E.L., 2014. Microbial community dynamics and stability during an ammonia-induced shift to syntrophic acetate oxidation. Appl. Environ. Microbiol. 80, 3375-3383. 
[43] Westerholm, M., Leven, L., Schnurer, A., 2012. Bioaugmentation of syntrophic acetate-oxidizing culture in biogas reactors exposed to increasing levels of ammonia. Appl. Environ. Microbiol. 78, 7619-25.

[44] Wolin, E.A., Wolin, M.J., Wolfe, R.S., 1963. Formation of methane by bacterial extracts. J. Biol. Chem. 238, 2882-2886.

[45] Wu, G., Healy, M.G., Zhan, X., 2009. Effect of the solid content on anaerobic digestion of meat and bone meal. Bioresour. Technol. 100, 4326-4331.

[46] Yang, Z., Guo, R., Xu, X., Wang, L., Dai, M., 2016. Enhanced methane production via repeated batch bioaugmentation pattern of enriched microbial consortia. Bioresour. Technol. 216, 471-7.

[47] Yenigün, O., Demirel, B., 2013. Ammonia inhibition in anaerobic digestion: A review. Process Biochem. 48, 901-911.

[48] Yoon, S.K., Kang, W.K., Park, T.H., 1994. Fed-batch operation of recombinant Escherichia coli containing trp promoter with controlled specific growth rate. Biotechnol. Bioeng. 43, 995-999.

[49] Zhang, J., Guo, R.B., Qiu, Y.L., Qiao, J.T., Yuan, X.Z., Shi, X.S., Wang, C.S., 2015. Bioaugmentation with an acetate-type fermentation bacterium Acetobacteroides hydrogenigenes improves methane production from corn straw. Bioresour. Technol. $179,306-13$.

[50] Zhang, L., Lee, Y.W., Jahng, D., 2012. Ammonia stripping for enhanced biomethanization of piggery wastewater. J. Hazard. Mater. 199-200, 36-42. 


\section{Figure Legends}

Fig. 1. Methane production of batch acclimation method, (A) direct-exposure at mesophilic condition, (B) direct-exposure at thermophilic condition, (C) stepwise-exposure at mesophilic condition, (D) stepwise-exposure at thermophilic condition.

Fig. 2. Methane accumulation at (A) mesophilic and (B) thermophilic reactor; $\mathrm{pH}$ fluctuation and total VFA accumulation at (C) mesophilic and (D) thermophilic condition during fed-batch acclimation method

Fig. 3. Methane yield at (A) mesophilic and (B) thermophilic reactor, pH fluctuation and total VFA accumulation at (C) mesophilic and (D) thermophilic condition during CSTR acclimation method

Fig. 4. SMA test results of mesophilic batch direct-exposure (MBD), mesophilic batch stepwise-exposure (MBS), mesophilic fed-batch (MFB), mesophilic CSTR (MCS), thermophilic batch direct-exposure (TBD), thermophilic batch stepwise-exposure (TBS), thermophilic fed-batch (TFB) and thermophilic CSTR (TCS). 

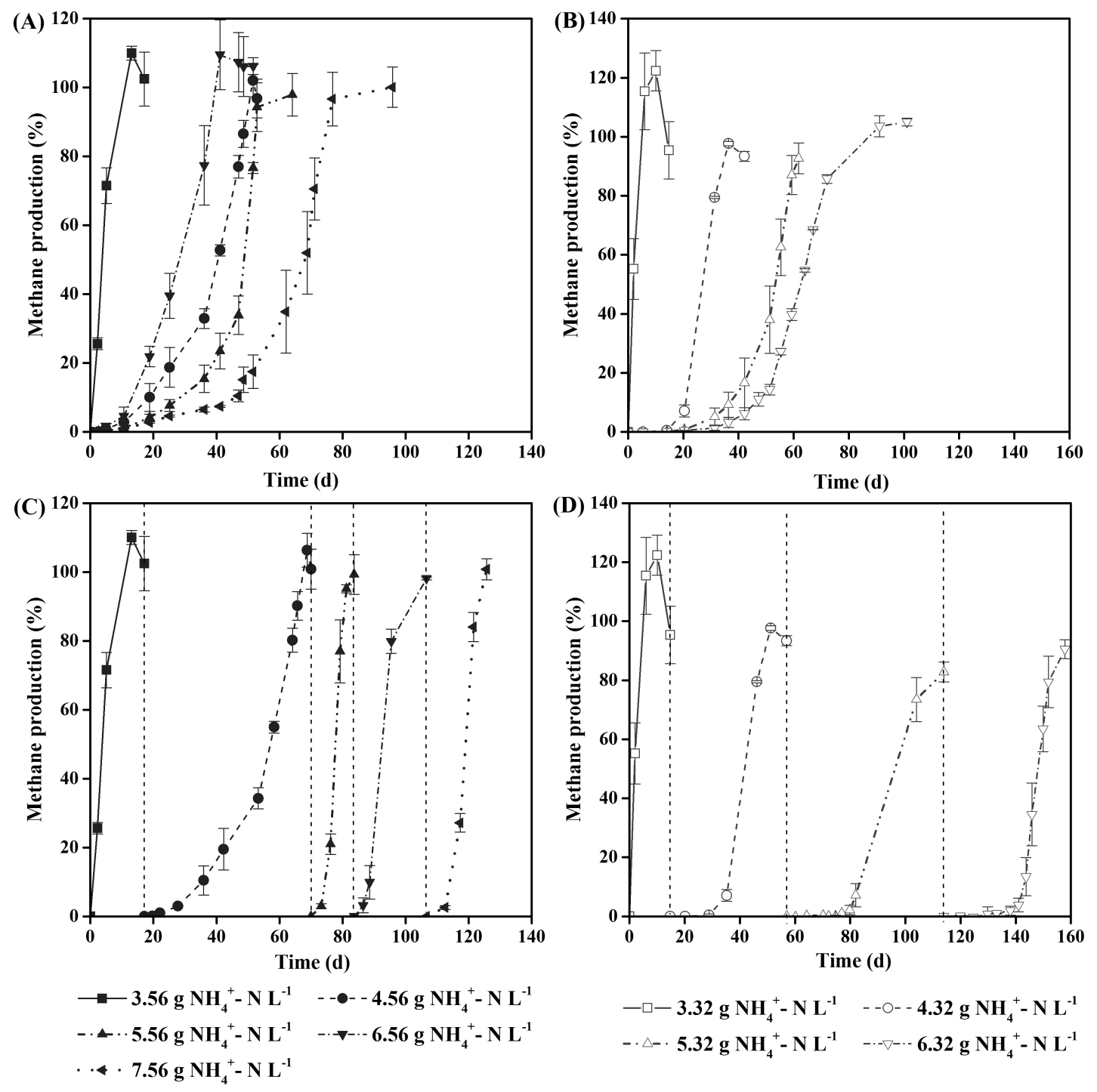

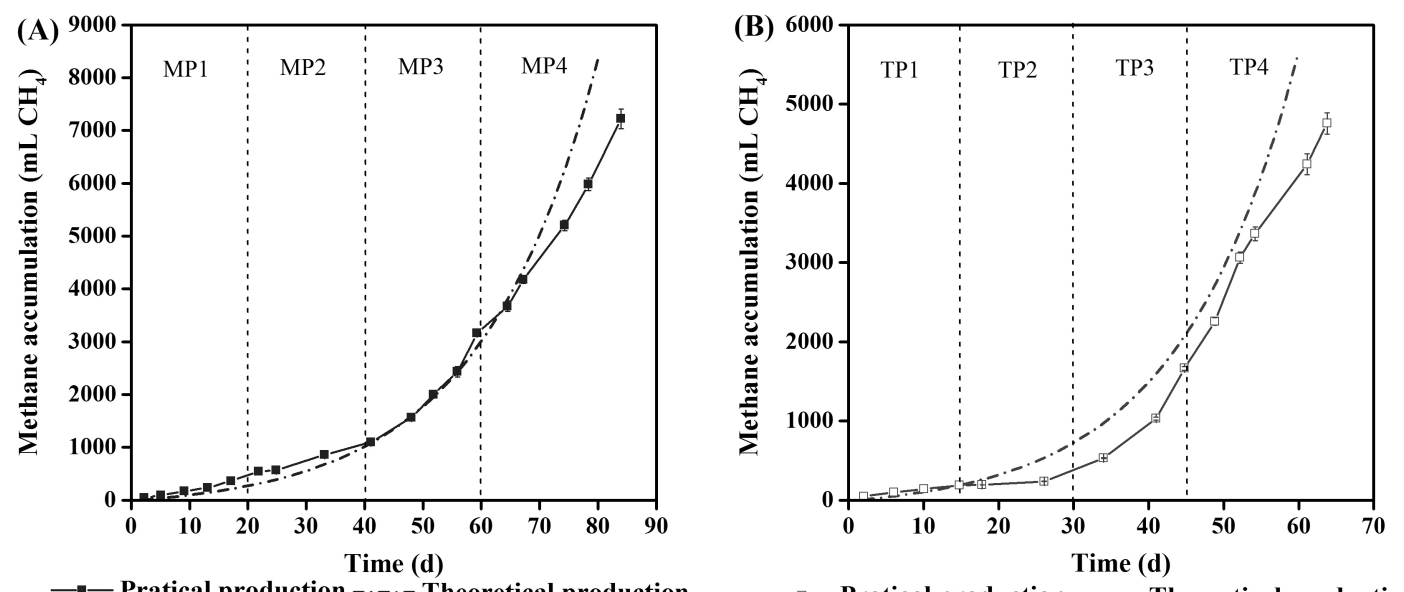

- - Pratical production --.-- Theoretical production

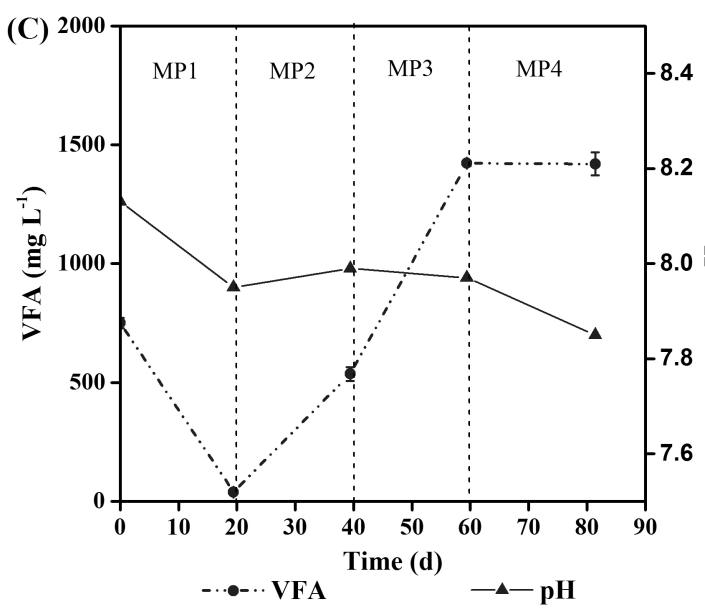

$\square-$ Pratical production -.-.- Theoretical production

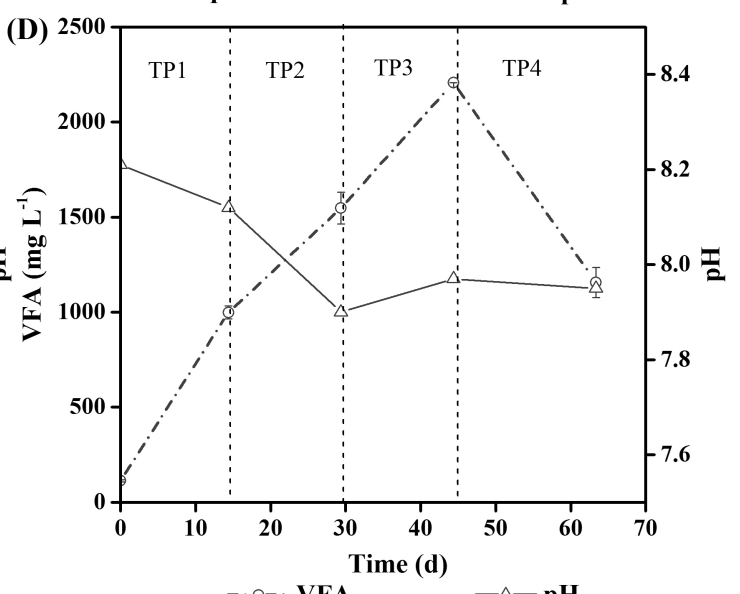

-.०-VFA $\quad \triangle-\mathrm{pH}$ 

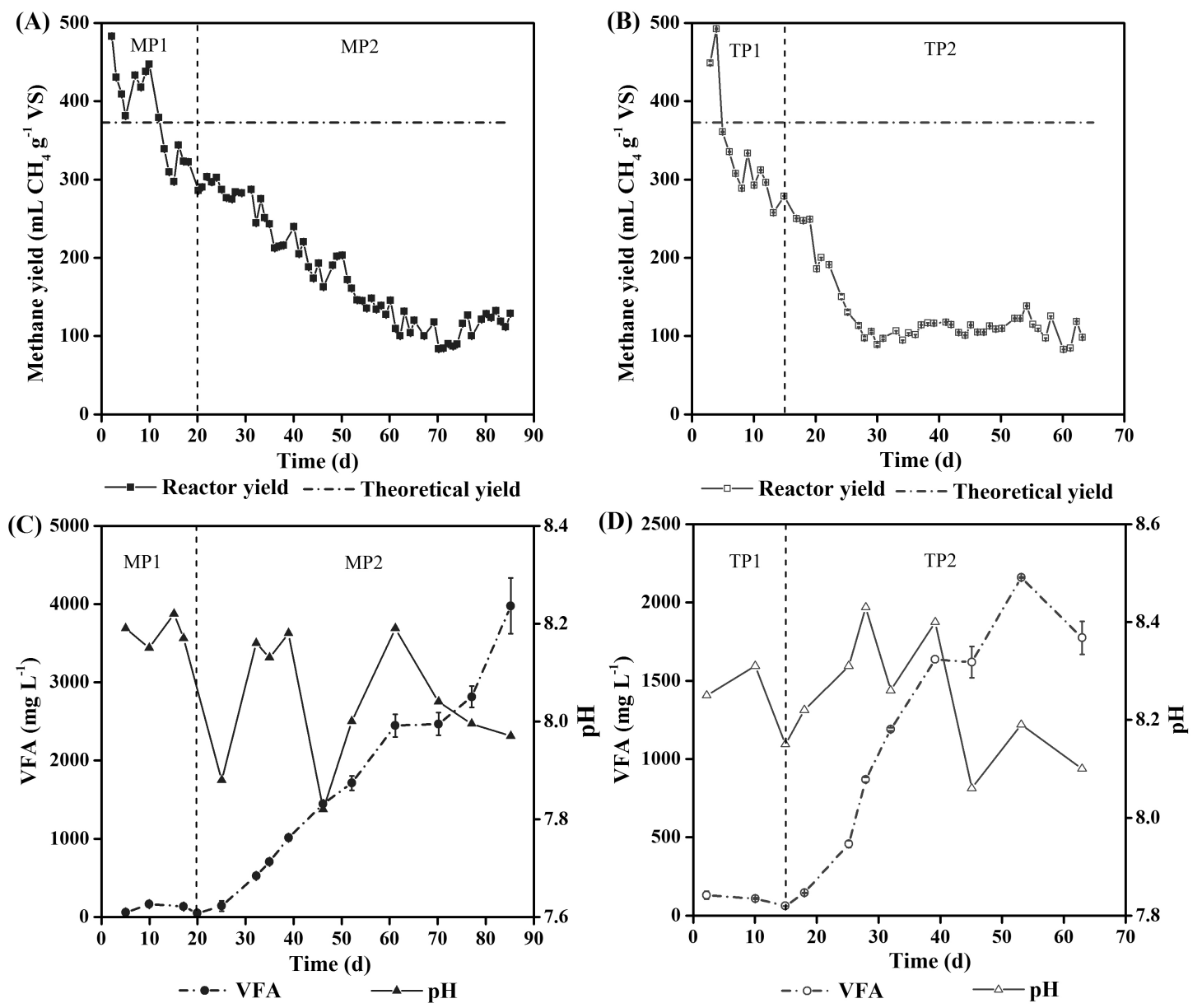


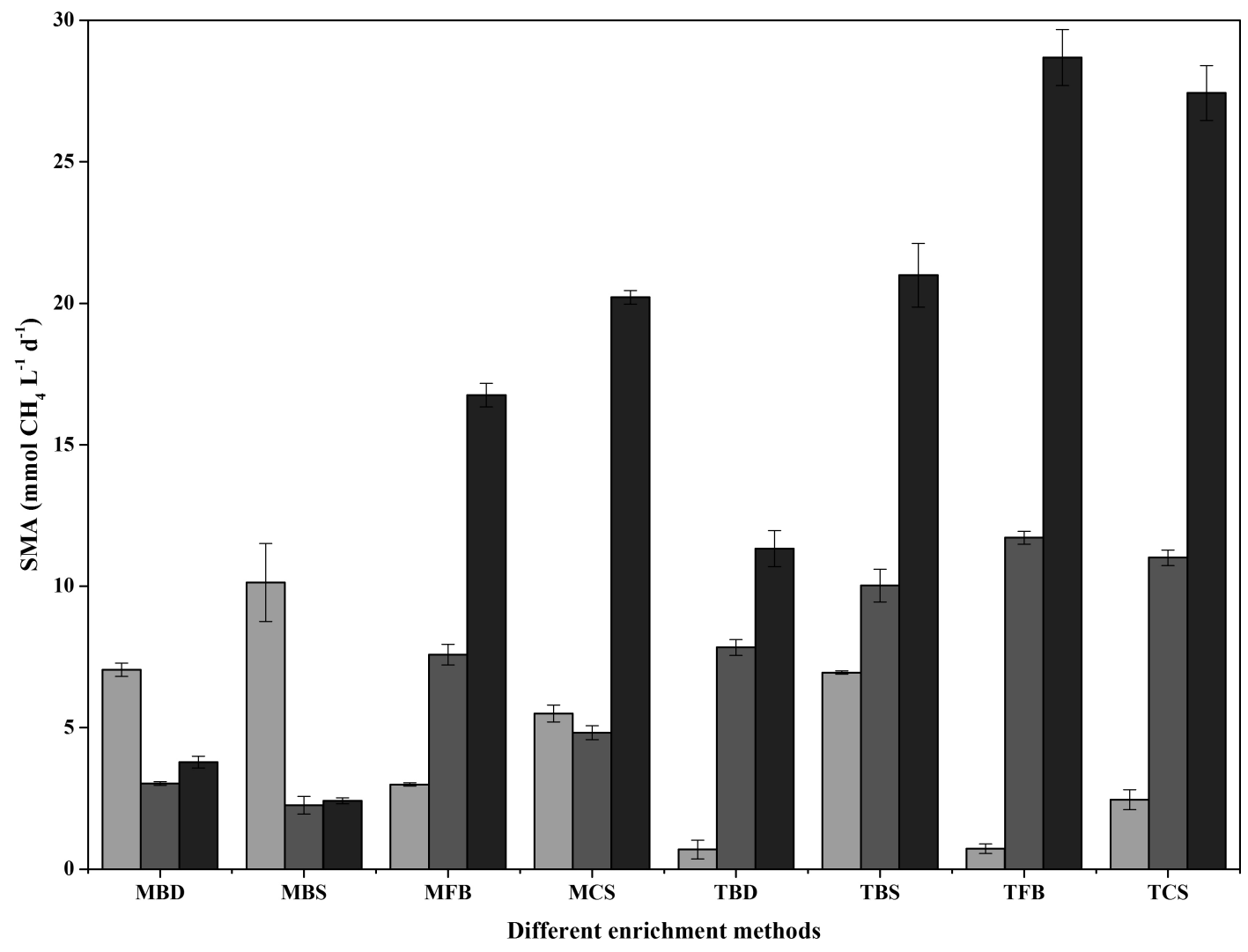

Acetate

$\square \mathrm{H}_{2} / \mathrm{CO}_{2}$

Formate 
Table 1. Characteristics of the inocula

\begin{tabular}{|c|c|c|}
\hline Parameter & $\begin{array}{l}\text { Mesophilic } \\
\text { value } \pm \text { SD }^{\text {a }}\end{array}$ & $\begin{array}{l}\text { Thermophilic } \\
\text { value } \pm \mathrm{SD}^{\text {a }}\end{array}$ \\
\hline Total solids, $\mathrm{TS}\left(\mathrm{g} \mathrm{L}^{-1}\right)$ & $39.68 \pm 0.98$ & $30.12 \pm 0.02$ \\
\hline Volatile solids, VS (g L $\left.\mathbf{L}^{-1}\right)$ & $27.82 \pm 0.01$ & $19.22 \pm 0.00$ \\
\hline Total Kjeldahl nitrogen, TKN (g N L $\left.\mathbf{L}^{-1}\right)$ & $5.15 \pm 0.50$ & $5.39 \pm 0.04$ \\
\hline Total ammonia nitrogen, TAN $\left(\mathrm{g} \mathrm{NH}_{4}{ }^{+}-\mathrm{N} \cdot \mathbf{L}^{-1}\right)$ & $3.56 \pm 0.09$ & $3.32 \pm 0.04$ \\
\hline Free ammonia $^{b}$, FAN $\left(\mathrm{g} \mathrm{NH}_{3}-\mathbf{N} \cdot \mathbf{L}^{-1}\right)$ & $0.53 \pm 0.01$ & $.29 \pm 0.02$ \\
\hline pH & 8.13 & 8.21 \\
\hline Total volatile fatty acids, VFA $\left(\mathrm{g} \mathrm{L}^{-1}\right)$ & $0.750 \pm 0.028$ & $0.113 \pm 0.08$ \\
\hline Standard deviation & & \\
\hline
\end{tabular}


Table 2. Ammonia levels during the different acclimation steps for the three experimental assays

\begin{tabular}{|c|c|c|c|c|c|c|c|}
\hline \multicolumn{4}{|c|}{ Mesophilic inoculum } & \multicolumn{4}{|c|}{ Thermophilic inoculum } \\
\hline $\begin{array}{l}\text { Acclimation } \\
\text { step }\end{array}$ & Batch & Fed-batch & CSTR & $\begin{array}{l}\text { Acclimation } \\
\text { step }\end{array}$ & Batch & Fed-batch & CSTR \\
\hline MP1 (baseline) & 3.56 & 3.56 & 3.56 & TP1 (baseline) & 3.32 & 3.32 & 3.32 \\
\hline MP2 & 4.56 & 4.56 & 4.56 & TP2 & 4.32 & 4.32 & 4.32 \\
\hline MP3 & 5.56 & 5.56 & 5.56 & TP3 & 5.32 & 5.32 & 5.32 \\
\hline MP4 & 6.56 & 6.56 & 6.56 & TP4 & 6.32 & 6.32 & 6.32 \\
\hline MP5 & 7.56 & - & - & & - & - & - \\
\hline
\end{tabular}


Table 3. Comprehensive comparison between the three different acclimation methods

\begin{tabular}{|c|c|c|c|c|c|c|c|c|}
\hline & \multicolumn{4}{|c|}{ Mesophilic inoculum } & \multicolumn{4}{|c|}{ Thermophilic inoculum } \\
\hline & $\begin{array}{l}\text { Batch } \\
\text { direct }\end{array}$ & $\begin{array}{l}\text { Batch } \\
\text { stepwise }\end{array}$ & $\begin{array}{l}\text { Fed- } \\
\text { batch }\end{array}$ & CSTR & $\begin{array}{l}\text { Batch } \\
\text { direct }\end{array}$ & $\begin{array}{l}\text { Batch } \\
\text { stepwise }\end{array}$ & $\begin{array}{l}\text { Fed- } \\
\text { batch }\end{array}$ & CSTR \\
\hline $\begin{array}{l}\text { Highest TAN }\left(\mathrm{g} \mathrm{NH}_{4}{ }^{+}-\mathrm{N}\right. \\
\left.\mathrm{L}^{-1}\right)\end{array}$ & 7.56 & 7.56 & 6.56 & 4.56 & 6.32 & 6.32 & 6.32 & 4.32 \\
\hline $\begin{array}{l}\text { Highest FAN (mg } \mathrm{NH}_{3} \\
\left.\mathrm{~L}^{-1}\right)\end{array}$ & 208 & 181 & 549 & 490 & & 542 & 1633 & 1425 \\
\hline Incubation time (d) & 78 & 125 & 84 & & 91 & 158 & 64 & - \\
\hline $\begin{array}{l}\text { Methanogenic activity } \\
\left(\mathrm{mmol} \mathrm{CH}_{4} \mathrm{~L}^{-1} \mathbf{d}^{-1}\right)^{\mathrm{a}}\end{array}$ & 7.04 & 10.13 & 16.75 & 20.21 & 11.33 & 20.99 & 28.68 & 27.43 \\
\hline $\begin{array}{l}\text { Production efficiency } \\
(\%)\end{array}$ & 100 & & 86.5 & 32 & 100 & 100 & 83.9 & 30 \\
\hline
\end{tabular}

${ }^{\mathrm{a}}$ The maximum methanogenic activity from SMA results. 


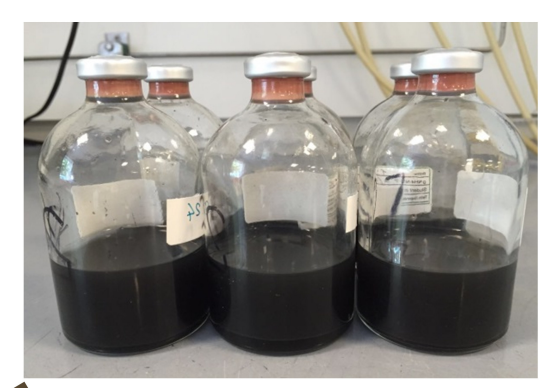

Batch

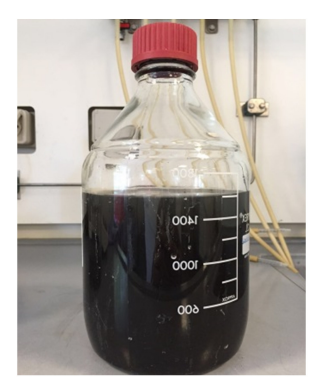

Fed-batch Acclimation

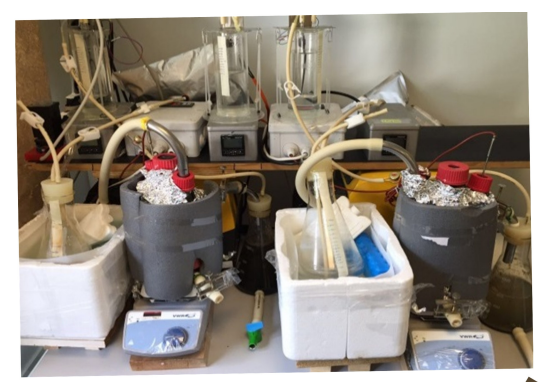

CSTR

Acclimation

\section{Assesșment}

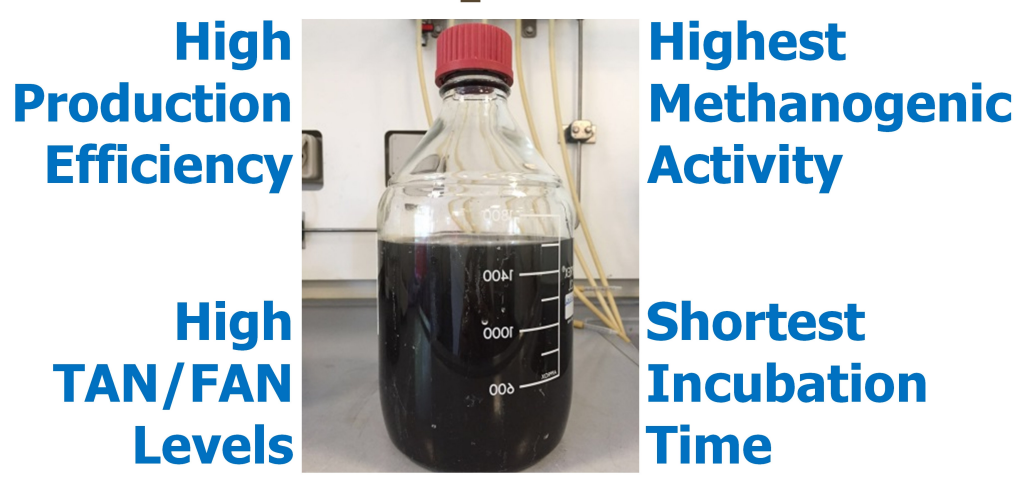




\section{Highlights}

- Fed-batch was the most efficient method to acclimatise ammonia tolerant consortia

- Fast acclimation of methanogens at extremely high FAN levels (1633 mg NH $3-\mathrm{N} \mathrm{L}^{-1}$ )

- Hydrogenotrophic methanogens were dominant at FAN levels above $540 \mathrm{mg} \mathrm{NH}-\mathrm{N} \mathrm{L}^{-1}$

- CSTR acclimation failed at low TAN level $\left(<4.6 \mathrm{~g} \mathrm{NH}_{4}{ }^{+}-\mathrm{N} \mathrm{L}^{-1}\right)$ due to washout effect

- Fed-batch is a promising acclimation method to be coupled with bioaugmentation 